Ivica Terzić ${ }^{1}$, Zoran Jeremić ${ }^{1}$, Tatjana Latas ${ }^{2}$ ${ }^{1}$ Singidunum University, Faculty of Business, Belgrade, Serbia

${ }^{2}$ Somborelektro d.o.o. Sombor

\title{
Modelling and Forecasting Volatility on Electric Power Exchange SEEPEX
}

DOI:10.7595/management.fon.2021.0002

Abstract:

Research Question: The launch and the beginning of trade on the South East Electric Power Exchange (SEEPEX) in Belgrade, early in 2016, opened the issue of forecasting volatility and price movements in the market. Motivation: The issue is of vital importance for all market actors for the purpose of maximising profits, reducing risks, planning production and making investment decisions. Forecasting volatility and price movements in electric power markets is important for traders with profit maximisation and yield-to-risk ratio optimisation in mind and, equally, for producers, large industrial consumers, investors and portfolio managers. Idea: Exploring models and techniques to forecast volatility in electricity markets and subsequently testing statistical methods based on time series data, the ARMA-GARCH being the preferred model, with a view to identifying optimal methods for this market. The volatility of the power market and price movements have been tested during a given period. The results can be used to gauge market parameters and opportunities to extrapolate future volatility and movements in electricity prices. Data: For the purposes of this analysis, a time series involving price movements and trade volumes were used, covering a period between the SEEPEX trade launch and the end of 2019. Tools: In the empirical part of the paper, "Stata 13" statistical and econometric software was used to explore stylised facts and model the volatility of SEEPEX electricity price returns. Findings: The authors offer an overview of different methods used in the research, having selected different specifications of the ARMA-GARCH model as the most reliable in predicting volatility in the given market. The exponential GARCH model with student-t error distribution is believed to have provided the best overall performance in modelling the SEEPEX return volatility, as well as the best volatility forecast. Contribution: This is one of the first empirical studies of the Serbian power market that deals with risk modelling. Forecasting time-varying electricity exchange volatility is important for all market participants interested in variance forecasts to be used to calculate risk and hedging measures.

Keywords: Electricity price, Forecasting, Modelling, Volatility, ARMA, GARCH, SEEPEX

JEL Classification: G17, C32, C51, C52, C53, C58

\section{Introduction}

SEEPEX a.d. Beograd is a licensed operator in an organised electricity market launched early in 2016. Clearly, SEEPEX is a very young power exchange in the early stages of development, making the time series required for an analysis of trade and overall market performance rather short. The authors studied trade data available between the birth of SEEPEX and the end of 2019, which is a long enough period to draw conclusions as to the possibility of predicting volatility and the price of power traded on SEEPEX in the observed period.

SEEPEX is a joint-stock company that emerged from a partnership between Elektromreža Srbije (EMS) national utility and EPEX SPOT. SEEPEX operates the organised market using standardised products and the day-ahead timeframe, providing electricity trading products in Serbia and across South-Eastern Europe, where possible. The organisation seeks to offer a transparent and reliable wholesale pricing mechanism in the electricity market by matching supply and demand at a fair and transparent price while ensuring that SEEPEX delivery and payment transactions are finalised. SEEPEX operates day-ahead auctions as a form of the spot market (www.seepex-spot.rs). 
Market deregulation and the beginning of electricity trading in Serbia have raised an important issue shared by all exchanges, trading in stocks and in commodities alike - the issue of different risks involved in a decision to go public. In finance, a study of market volatility is most relevant to a study of risks, whether financial and commodity markets, derivatives or currencies are involved. Based on a volatility analysis risks may be predicted and risk minimisation attempted, allowing also for the modelling of market trends and price movement forecasts (Nakamura et al., 2006). Volatility is essential in analysing power markets with high or ultra-high frequency data. (Chang, McAleer \& Tian, 2019). Accordingly, predicting the volatility of a power market is a key issue for all market players in the context of profit maximisation, risk/loss reduction, appropriate supply and demand for producers, consumers, traders, investors and portfolio managers. Among other things, market volatility forecasts can help producers formulate their offer and plan investments using modern assets pricing techniques. Still, it can also make it easier for consumers and traders to reduce the risks arising from price fluctuations and increase profits (Gianfreda, 2010).

Since not all power markets have reached the same stage of development, the literature suggests different price forecasting methods for specific markets (Cerjan, Petricic \& Delimar, 2019). Yet the previous and current energy literature on price forecasting has in good part focused on developed power markets. That on SEEPEX electricity price forecasting is rather scarce though. With that in mind, the main aim of this research is to fill the gap by introducing and testing one of the statistical approaches, based on ARMA-GARCH specification, for day-ahead electricity price forecasting on the domestic power market. The goal is to accurately capture the behaviour of the SEEPEX conditional volatility.

The paper is structured as follows. After Introduction, Section 2 provides a brief overview of the existing literature. Section 3 outlines the research approach and methodology. Section 4 describes data, discusses the study's empirical results, and explains the robustness tests used. Section 5 offers a summary and a conclusion.

\section{Literature Review}

A large number of competing methods exist to measure, model and predict energy price volatility, and it is important to note that no research has suggested any universal superiority of one method over the others. Instead, each method has merit and may work well in certain circumstances (Nomikos \& Andriosopoulos, 2012; Sisodiaa et al., 2015; Singh \& Mohanty, 2015). The results indicate a large variation in scientists' methodologies to address the issues in different countries (Sisodiaa et al., 2015).

There is also a broad spectrum of techniques and methods designed to predict market volatility and price movement on electricity exchanges as accurately as possible (Weron, 2014). Models used in short-term electricity price forecasting can be divided into three categories: statistical models based on time series analysis, models based on artificial neural networks and hybrid models (Abedinia et al., 2017). Specific features involved in power trading, alongside high volatility inherent in electricity markets, have made it impossible to use price forecasting methods employed by other exchanges without involving considerable power market-specific modifications and a number of intrinsic factors (Alfares \& Nazeeruddin, 2002). These include the impossibility of storing electricity, seasonality, the influence of weather on consumption and production, i.e., supply and demand, transport-related restrictions and risks (Nakamura et al., 2006).

Equally important is the range of forecasting - there can be short-term, medium-term or long-term forecasts (Mandal et al., 2007). Short-term forecasts are used for spot markets, largely day-ahead, as traders want to maximise profits and cut risks (Maciejowska \& Weron, 2015; Nomikos \& Andriosopoulos, 2012; Maksimov \& Shchurupova, 2017; Steinert \& Ziel, 2019; Ziel \& Weron, 2018; Hubicka, et al., 2019). Medium-term forecasts are used for bilateral negotiations between producers and consumers, while long-term planning requires long-term forecasts (Maciejowska \& Weron, 2016). The models based on artificial intelligence, most often neural networks, have been largely used for their ability to resolve undefined relationships between input and output variables, approximating complex nonlinear functions and implementing multiplied algorithms (Wang et al., 2006; Gonzalez et al. 2012; Monteiro et al., 2016; Dedinec \& Dedinec, 2017).

A variety of statistical forecasting models dominates Day-ahead spot markets, based on historical time series data and volatility measurements (Chang \& McAleer,2017; Nowotarski \& Weron, 2018; Maciejowska et al., 2019; Maciejowska \& Weron, 2015; Gianfreda, et al., 2020; Liu \& Shi, 2013; López-Gonzales, 2020). These models are used to predict future trends based on historical movement, where identified shapes and movements of time series from the past are extrapolated into predictions of the future (Kostrzewski \& Kostrzewska, 2019). 
SEEPEX day-ahead spot price forecasting has been recently researched in several papers. Dedinec \& Dedinec. (2017) used an artificial intelligence model (ANN) to predict day-ahead electricity prices in Bulgarian, Croatian and Serbian power exchanges. They obtained the best forecasting model performance for the Serbian market. Dedinec \& Dedinec (2018) also developed a forecasting model based on deep belief networks (DBN) and applied it successfully to the power markets in the South East Europe (SEE) region. The results show a superior forecasting performance of the newly developed model compared to traditional neural networks.

However, no attempts have been made so far to analyse and forecast the electricity price dynamics on this market using a statistical approach. Hence the attempt to fill the research gap by developing empirical forecasting models based on ARMA-GARCH specifications.

\section{Research Methodology}

For the purpose of predicting the volatility of returns in a power market, the authors use different symmetrical and asymmetrical models from the Generalised Auto Regressive Conditional Heteroskedasticity (GARCH) family.

Modelling and forecasting volatility are crucial for investors who are interested in a predicted variance of time-varying electricity price returns over an investment period. GARCH models are designed to capture the volatility clustering effects on the returns. On the other hand, the standard GARCH models such as GARCH $(1,1)$ cannot account for leverage effects (Awartani \& Corradi, 2005). These asymmetries occur as volatility responds to positive or negative returns. The standard $\mathrm{GARCH}$ model cannot capture these, since the lagged error term is squared, therefore losing its sign. A number of GARCH models are designed to capture asymmetry and leverage effects. Those of relevance, discussed in this paper, include EGARCH, GJR GARCH and SAGARCH.

The basic GARCH model was developed by Bollerslev (1986) and has the following form:

$$
\sigma_{t}^{2}=\omega+\sum_{i=1}^{q} \alpha_{i} \varepsilon_{t-i}^{2}+\sum_{j=1}^{p} \beta_{j} \sigma_{t-j}^{2}
$$

The exponential GARCH (EGARCH) model was developed by Nelson (1991). The EGARCH (p, q) model specifies conditional variance in logarithmic form, which means that there is no need to impose an estimation constraint in order to avoid negative variance. Accordingly, there is no need to impose non-negativity constraints artificially.

The conditional variance equations for the EGARCH is as follows:

$$
\log \left(\sigma_{t}^{2}\right)=\omega+\sum_{i=1}^{q}\left[\alpha_{i} z_{t-i}+\gamma_{i}\left(\left|z_{t-1}\right|-\sqrt{2 / \pi}\right)\right]+\sum_{j=1}^{p} \beta_{j} \log \left(\sigma_{t-j}^{2}\right)
$$

This specification captures the stylised fact that a negative shock leads to a higher conditional variance in the subsequent period than a positive shock.

The model that also allows for asymmetrical dependencies includes the GJR-GARCH (Glosten, Jagannathan and Runkle, 1993) as shown below:

$$
\sigma_{t}^{2}=\omega+\sum_{i=1}^{q}\left[\alpha_{i}+\gamma_{i} I_{\left(\varepsilon_{t-i}>0\right)}\right] \varepsilon_{t-i}^{2}+\sum_{j=1}^{p} \beta_{j} \sigma_{t-j}^{2}
$$

The simple asymmetric GARCH or SAGARCH model simply adds another parameter to the symmetric GARCH model so that it can have a mechanism to capture the asymmetric volatility response. The simple asymmetric GARCH model was initially suggested by Engle (1990) and subsequently discussed by Engle and $\mathrm{Ng}$ (1993). This model takes the form presented below:

$$
\sigma_{t}^{2}=\omega+\alpha\left(\varepsilon_{t-1}-\lambda\right)^{2}+\beta \sigma_{t-1}^{2}
$$


where the extra parameter captures the leveraqe effect. SAGARCH conditional variance depends on the extra parameter $\lambda$. If $\lambda>0$, then term $\left(\varepsilon_{t-1}-\lambda\right)^{2}$ will be larger when the shock is negative. If $\lambda<0$, the opposite will happen (Alexander, 2008).

The parameter estimates were checked using several diagnostic analysis tools. The final model selection is conducted in compliance with econometric theory primarily relying on log likelihood function (LLF), the Akaike information criterion (AIC) and Bayesian information criterion (BIC). All calculations and empirical investigations are conducted using STATA 13 software package.

\section{Results and Discussion}

Daily historical data referring to the SEEPEX prices from 18 February 2016 until 31 December 2019 were available on the SEEPEX web page (www.seepex-spot.rs). Using the same data set for each, eight ARMAGARCH models were used to capture volatility clustering and forecasting. The price series is converted to log returns series. For a series of SEEPEX prices SPt, the rate of return $r t$ is obtained by:

$$
r_{t}=\log \left(\frac{S P_{t}}{S P_{t-1}}\right)
$$

The SEEPEX historical prices and logarithmic returns are presented in Figure 1. The graph clearly shows that the SEEPEX time series are very volatile, with very high volatility spikes in the observed period.

Before analysing different GARCH models' predictive performance, some stylised facts about SEEPEX log return series have been tested and presented in Tables 1 - 6.

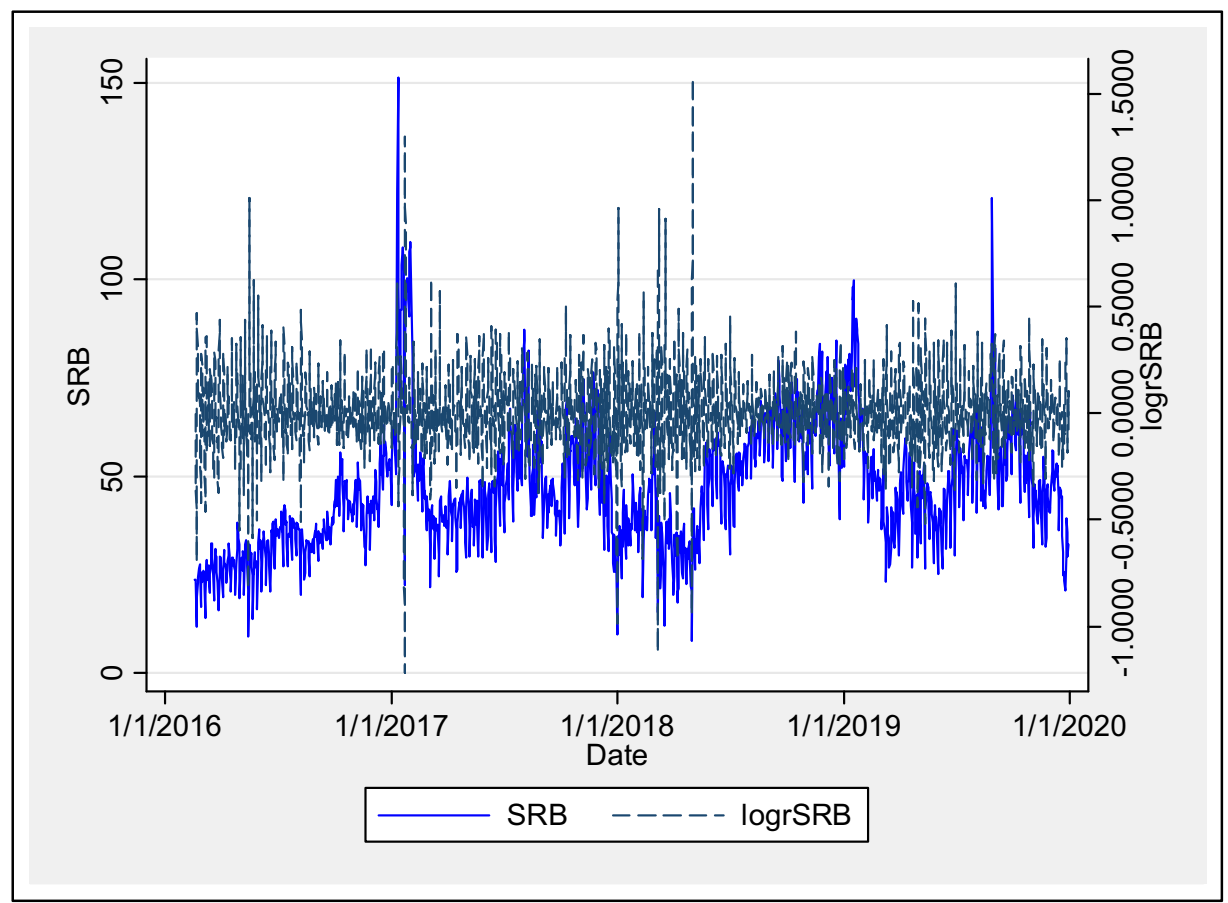

Figure 1: SEEPEX historical prices and log returns, February 2016 - December 2019

Table 1: Descriptive statistics of SEEPEX log returns

\begin{tabular}{|r|cccccc|}
\hline Variable & mean & sd & skewness & kurtosis & min & max \\
\hline log r SRB & 0.0002204 & 0.1968394 & 0.5405021 & 11.09913 & -1.21836 & 1.573098 \\
\hline
\end{tabular}

Source: Authors' calculation 
Table 1 shows the descriptive statistics of SEEPEX daily log returns. The return mean is close to zero. The unconditional daily standard deviations are very high (19.68\%), which implies that the power market is relatively very volatile, as confirmed by the difference between the minimum $(-121.84 \%)$ and maximum (157.31\%) daily returns. Electricity returns have a leptokurtic distribution (fat tails), verified by the analysis of asymmetry and kurtosis coefficients. SEEPEX log returns exhibit kurtosis well above 3 (11.09), indicating a higher probability of the occurrence of extreme returns than predicted by Gaussian distribution. Also, there is a presence of skewness. In fact, SEEPEX series are positively skewed (0.54). The positive skew means that the lower tail of the distribution is heavier and the centre is shifted to the left. It points to a higher likelihood of achieving extreme positive returns on the Serbian power market.

Figure 2. also shows skewed SEEPEX returns, and leptokurtic unconditional distribution. The distribution has a higher peak and heavier tails than the normal density with the same variance.

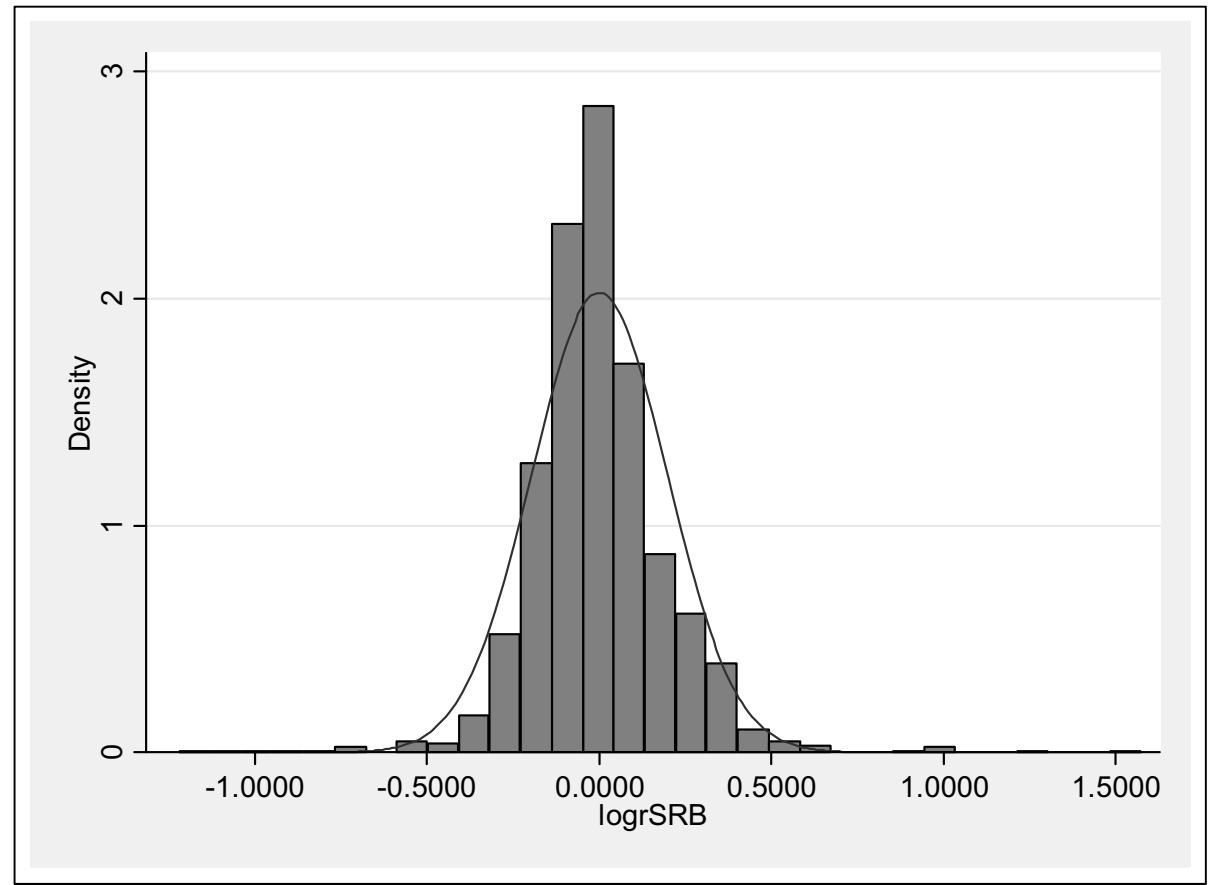

Figure 2: Histogram of SEEPEX log returns

These indicate that the SEEPEX log return series are non-normal. This non-normality is corroborated via Shapiro-Wilk and Skewness/Kurtosis tests for normal data, as presented in Tables 2 and 3. The results obtained by test statistics lead to the rejection of normality's null hypothesis, and both tests show that data are not normally distributed.

Table 2: Shapiro-Wilk W test for normal data

\begin{tabular}{|r|ccccc|}
\hline Variable & Obs & W & V & z & Prob $>\mathbf{z}$ \\
\hline log r SRB & 1412 & 0.9180 & 70.8550 & 10.697 & 0.0000 \\
\hline
\end{tabular}

Source: Authors' calculations

Table 3: Skewness/Kurtosis tests for Normality

\begin{tabular}{|r|ccccc|}
\hline \multicolumn{1}{|c}{} & & & \multicolumn{2}{c|}{ joint- } \\
\hline Variable & Obs & Pr (Skewness) & Pr (Kurtosis) & chi2 (2) & Prob >chi2 \\
\hline log r SRB & 1412 & 0.0000 & 0.0000 & 288.67 & 0.0000 \\
\hline
\end{tabular}

Source: Authors' calculations

In further data analysis, the Dickey-Fuller test was used to examine stochastic trends. The results are presented in Table 4. The null hypothesis is rejected that SEEPEX log returns have a unit root, because the $Z$ score test statistic $(-34,673)$ does not fall within the acceptance interval. It means the series of log returns are stationary for any level of confidence. 
Table 4: Augmented Dickey-Fuller test for unit root

\begin{tabular}{|c|c|c|c|c|}
\hline & \multirow[b]{2}{*}{$\begin{array}{c}\text { Test } \\
\text { Statistic }\end{array}$} & \multicolumn{3}{|c|}{ _ Interpolated Dickey-Fuller } \\
\hline & & $\begin{array}{c}1 \% \text { Critical } \\
\text { Value }\end{array}$ & $\begin{array}{l}5 \% \text { Critical } \\
\text { Value }\end{array}$ & $\begin{array}{l}10 \% \text { Critical } \\
\text { Value }\end{array}$ \\
\hline $\mathrm{Z}(\mathrm{t})$ & -34.673 & -3.43 & -2.86 & -2.57 \\
\hline
\end{tabular}

MacKinnon approximate $p$-value for $Z(t)=0.0000$

Source: Authors' calculations

Given that returns are not normally distributed, the conditional mean needs to be modelled prior to the volatility analysis that will be included in the GARCH process. This part of the research aims to build an ARMA model for electricity price changes, estimating it in three stages. Firstly, a model is identified by determining the order of the model required to capture the data's dynamic features (Enders, 2010). Graphical procedures and information criteria are used to determine the most appropriate specification. Secondly, the parameters of the model are estimated. Finally, a model diagnostic check is performed using a residual analysis.

As it can be seen clearly from Table 5, the SEEPEX series are quite persistent. The autocorrelation function dies away slowly. The first seven partial autocorrelation coefficients appear strongly significant. Since the first autocorrelation coefficient is highly significant, the joint test statistic presented in column 4 rejects the null hypothesis of no autocorrelation at the $1 \%$ level for all numbers of lags considered. It could be concluded that a mixed ARMA process might be appropriate, although it is difficult to precisely determine the appropriate order given these results. In order to investigate this issue further, information criteria are employed.

Table 5: Ljung-Box Q test statistics (white noise test) for auto-correlation in SEEPEX log returns

\begin{tabular}{|lcccl|}
\hline LAG & AC & PAC & \multicolumn{1}{c}{$\mathbf{Q}$} & Prob $>\mathbf{Q}$ \\
\hline 1 & -0.1510 & -0.1510 & 32.253 & 0.0000 \\
2 & -0.2235 & -0.2521 & 102.97 & 0.0000 \\
3 & -0.0825 & -0.1780 & 112.62 & 0.0000 \\
4 & -0.0778 & -0.2115 & 121.21 & 0.0000 \\
5 & -0.1365 & -0.3176 & 147.65 & 0.0000 \\
6 & -0.0312 & -0.3329 & 149.03 & 0.0000 \\
7 & 0.4755 & 0.2597 & 470.3 & 0.0000 \\
8 & -0.0335 & 0.0322 & 471.9 & 0.0000 \\
9 & -0.1162 & 0.0550 & 491.12 & 0.0000 \\
10 & -0.0757 & 0.0023 & 499.27 & 0.0000 \\
\hline
\end{tabular}

Source: Authors' calculations

Based on the autocorrelations, partial autocorrelations, and the results of preliminary estimations, AR (7) MA (1 7) model is identified in the log-differenced series of SEEPEX electricity prices (Table 5). As the estimation results have been examined, it can be seen from Table 6 that the AR (7) coefficient is 0.9823, the MA (1) and MA (7) coefficients are -0.0281 and -0.8857 respectively, and all are highly significant ( $p$-values are bellow 0.05). Also, AIC and BIC statistics are generated for the competing ARMA models, and this ARMA model has been confirmed to be with the lowest information criterion.

In addition to an autoregressive term and an MA (1) term, an MA (7) term is included to account for a remaining weekly effect. Thus, the model to be fit is:

$$
r_{t}=-0.037+0.982\left(r_{t-7}+0.037\right)-0.028 \varepsilon_{t-1}-0.886 \varepsilon_{t-7}+\varepsilon_{t}
$$


Table 6: ARMA process coefficients estimates

\begin{tabular}{|c|c|cccc|}
\hline \multicolumn{2}{|c|}{ ARMA mean equation } & \multicolumn{5}{|c|}{ SEEPEX } \\
\cline { 1 - 5 } Order & Parameters & Coef. & Std. Err. & $z$ & $p$ \\
\cline { 2 - 5 } & Cons & -0.0374174 & 0.0106822 & -3.5 & 0 \\
\cline { 1 - 1 }$L 7$ & AR & 0.9823808 & 0.0032965 & 298 & 0 \\
\cline { 1 - 1 }$L 1$ & MA & -0.0281331 & 0.0084905 & -3.31 & 0.001 \\
\cline { 1 - 1 } L7 & MA & -0.8857268 & 0.0119572 & -74.07 & 0 \\
\hline
\end{tabular}

Source: Authors' calculations

In this final specification, the SEEPEX returns are still highly autocorrelated at a level of 0.982 , though innovations have a negative impact on the ensuing day $(-0.028)$ and a negative impact of 0,886 on the eighth day of trading.

After generating residuals from ARMA model, a constant-only model is fit by OLS and tested for the presence of autoregressive conditional heteroskedasticity using Engle's Lagrange multiplier test (LM test).

The LM test (Table 7) shows p-values of zero for different lags, which are below 0.05 , and the null hypothesis of no ARCH effects is rejected. This makes the SEEPEX log return series a good candidate for ARCH modelling.

Table 7: LM test for autoregressive conditional heteroskedasticity (ARCH effect)

\begin{tabular}{|c|ccc|}
\hline Lags $(\mathbf{p})$ & chi2 & df & Prob > chi2 \\
\hline 1 & 100.781 & 1 & 0.0000 \\
2 & 100.686 & 2 & 0.0000 \\
3 & 103.536 & 3 & 0.0000 \\
4 & 103.902 & 4 & 0.0000 \\
5 & 104.838 & 5 & 0.0000 \\
6 & 123.273 & 6 & 0.0000 \\
7 & 132.939 & 7 & 0.0000 \\
8 & 132.913 & 8 & 0.0000 \\
9 & 133.283 & 9 & 0.0000 \\
10 & 135.542 & 10 & 0.0000 \\
11 & 135.455 & 11 & 0.0000 \\
12 & 140.529 & 12 & 0.0000 \\
13 & 140.600 & 13 & 0.0000 \\
14 & 140.512 & 14 & 0.0000 \\
15 & 140.800 & 15 & 0.0000 \\
H0: no ARCH effects vs. H1: ARCH(p) disturbance \\
\hline
\end{tabular}

Source: Authors' calculations

In the next section the results of estimating eight different ARMA - GARCH models using the SEEPEX data set are compared. Different volatility forecasting models assuming the errors that follow both Gaussian and student-t distribution are fitted, namely: GARCH (Bollerslev 1986), EGARCH (Nelson 1991), SAARCH, simple asymmetric ARCH (Engle, 1990) and GJR GARCH (Glosten et al., 1993), a form of TARCH (Zakoian, 1994). All GARCH models have a specification for both the conditional mean (Equation 6) and the conditional variance, and the variance is a function of the size of prior unanticipated innovations (i.e., shock).

The models' estimate is made using daily SEEPEX log returns from 18 February 2016 to 31 December 2019. The estimated coefficients for the different GARCH models are shown in Table 8 with their standard errors, $t$ statistics and $p$-values. All GARCH parameters are estimated by maximizing the log likelihood function. The parameter estimates are statistically significant to a high degree, at a $5 \%$ level collectively (Table 8 , column 6 ). It is also worth noting that the asymmetry term in the EGARCH, GJR GARCH and SAGARCH models is statistically significant. Some practical implications and interpretation of obtained GARCH parameters can be derived as follows: 
- The volatility intercept $(\omega)$ is very close to zero in all applied models, except for the EGARCH (EGARCH does not require any constraints on parameters). All constraints for the GARCH models are fulfilled. The sum of $\alpha+\beta$ is lower than 1 ; thus the process is covariance stationary. The sum of coefficients $\alpha+\beta$ falls in the interval 0.84-0.94. The estimations show that coefficient $\alpha$ has small values relative to $\beta$. But all GARCH models for SEEPEX stipulate that coefficient $\alpha$ is larger than 0.1 (in the interval $0.21-0.41$ ). It results in a larger volatility rise following a shock in time t-1. Volatility persistence $(\beta)$ for SEEPEX in all models (range 0.65 to 0.86 ) is lower than 0.9 , which means that the reaction of volatility to past market movements is much more intense and sensitive to market shocks, and as a result, today's volatility is highly correlated to yesterday's and shocks in volatility subside quickly. It indicates a relatively short-term persistence of the estimated volatility.

- In the case of EGARCH, a response exists only to positive shocks due to the positive asymmetry term. This is a strong indication of the asymmetry effect, but the leverage effect is not possible. Asymmetry is also possible for GJR GARCH and SA GARCH, but leverage is not. These findings are in line with Chang \& McAleer (2017). The positive EARCH_a $(\theta)$ coefficient 0.358 implies that positive shocks (SEEPEX price increases) are more destabilising than negative innovations. If $\theta>0$ and $\alpha<0$, volatility reacts to bad news more than it does to the good news. In an electricity power market, a price increase is bad news. The asymmetry parameters estimated in GJR $(-0.35)$ and SA GARCH $(-0.02)$ models are negative, as they would be expected to be on commodity markets, but also with the absence of leverage. The asymmetric models also appear to be a better fit than the symmetric model because the log likelihood value is higher.

Table 8: Different GARCH parameter estimates

\begin{tabular}{|c|c|c|c|c|c|}
\hline \multicolumn{2}{|c|}{ GARCH type models } & \multicolumn{4}{|c|}{ SEEPEX } \\
\hline $\operatorname{Order}(1,1)$ & Parametrs & Coef. & Std. Err. & $z$ & $p$ \\
\hline \multirow{3}{*}{$\begin{array}{l}\text { GARCH } \\
\text { Gaussian }\end{array}$} & Intercept $(\omega)$ & $1.72 \mathrm{E}-03$ & $2.09 \mathrm{E}-04$ & 8.22 & 0.000 \\
\hline & $\mathrm{ARCH}(\alpha)$ & 0.2407171 & 0.0170084 & 14.15 & 0.000 \\
\hline & GARCH $(\beta)$ & 0.7097634 & 0.0181402 & 39.13 & 0.000 \\
\hline \multirow{3}{*}{ GARCH t } & Intercept $(\omega)$ & $2.87 \mathrm{E}-03$ & $6.35 \mathrm{E}-04$ & 4.51 & 0.000 \\
\hline & $\mathrm{ARCH}(\alpha)$ & 0.23402 & 0.0438703 & 5.33 & 0.000 \\
\hline & $\operatorname{GARCH}(\beta)$ & 0.6374336 & 0.0501821 & 12.7 & 0.000 \\
\hline \multirow{4}{*}{$\begin{array}{l}\text { EGARCH } \\
\text { Gaussian }\end{array}$} & Intercept $(\omega)$ & -0.5376347 & 0.0615906 & -8.73 & 0.000 \\
\hline & $\mathrm{ARCH}(\alpha)$ & -0.1879445 & 0.0162286 & -11.58 & 0.000 \\
\hline & $\operatorname{GARCH}(\beta)$ & 0.8610962 & 0.0149187 & 57.72 & 0.000 \\
\hline & $\mathrm{EARCH}$ a $(\theta)$ & 0.372327 & 0.0243169 & 15.31 & 0.000 \\
\hline \multirow{4}{*}{ EGARCH t } & Intercept $(\omega)$ & -0.6712975 & 0.1430532 & -4.69 & 0.000 \\
\hline & $\mathrm{ARCH}(\alpha)$ & -0.1747658 & 0.0381033 & -4.59 & 0.000 \\
\hline & GARCH $(\beta)$ & 0.8319856 & 0.0347353 & 23.95 & 0.000 \\
\hline & EARCH_a $(\theta)$ & 0.3576924 & 0.0508204 & 7.04 & 0.000 \\
\hline \multirow{4}{*}{$\begin{array}{l}\text { GJR GARCH } \\
\text { Gaussian }\end{array}$} & Intercept $(\omega)$ & $2.33 \mathrm{E}-03$ & $2.56 \mathrm{E}-04$ & 9.1 & 0.000 \\
\hline & $\mathrm{ARCH}(\alpha)$ & 0.4190204 & 0.0309391 & 13.54 & 0.000 \\
\hline & GARCH $(\beta)$ & 0.681642 & 0.0217778 & 31.3 & 0.000 \\
\hline & TARCH $(\mathrm{Y})$ & -0.3578884 & 0.0324027 & -11.05 & 0.000 \\
\hline \multirow{4}{*}{ GJR GARCH t } & Intercept $(\omega)$ & $2.86 \mathrm{E}-03$ & 5.83E-04 & 4.91 & 0.000 \\
\hline & $\mathrm{ARCH}(\alpha)$ & 0.3994211 & 0.0790492 & 5.05 & 0.000 \\
\hline & $\operatorname{GARCH}(\beta)$ & 0.6466886 & 0.0474028 & 13.64 & 0.000 \\
\hline & TARCH $(\mathrm{Y})$ & -0.3480306 & 0.0818433 & -4.25 & 0.000 \\
\hline \multirow{4}{*}{$\begin{array}{l}\text { SAGARCH } \\
\text { Gaussian }\end{array}$} & Intercept $(\omega)$ & $2.46 \mathrm{E}-03$ & 3.00E-04 & 8.17 & 0.000 \\
\hline & $\mathrm{ARCH}(\alpha)$ & 0.218619 & 0.0171941 & 12.71 & 0.000 \\
\hline & GARCH $(\beta)$ & 0.6866569 & 0.0207388 & 33.11 & 0.000 \\
\hline & SAARCH ( $\mathrm{Y} 2)$ & -0.0253384 & 0.0030808 & -8.22 & 0.000 \\
\hline \multirow{4}{*}{ SAGARCH t } & Intercept $(\omega)$ & $2.94 \mathrm{E}-03$ & 6.36E-04 & 4.63 & 0.000 \\
\hline & $\mathrm{ARCH}(\alpha)$ & 0.2071993 & 0.0407998 & 5.08 & 0.000 \\
\hline & $\operatorname{GARCH}(\beta)$ & 0.6531502 & 0.0500054 & 13.06 & 0.000 \\
\hline & SAARCH (y2) & -0.0230343 & 0.0073476 & -3.13 & 0.002 \\
\hline
\end{tabular}

Source: Authors' calculations 
The estimates of the maximised value of the LLF, AIC and BIC information criteria are shown in Table 9. The maximum LLF value for the EGARCH with student-t error distribution model is considerably higher than either GJR or symmetric GARCH. Accordingly, the E-GARCH t model provides the best fit to this sample of all the models considered so far. In terms of the AIC and BIC values, too, EGARCH t is the preferable model (producing the smallest $\mathrm{AIC}$ and $\mathrm{BIC}$ values). This leads to a conclusion that EGARCH $t$ fits the sample data best, but it does not necessarily mean that it will outperform the other volatility forecasting models. The issue warrants further research. As for SEEPEX series, the long-term volatility from EGARCH $\mathrm{t}$ is also lower than in the GJR GARCH, SAGARCH or symmetric GARCH models.

Compared to previous findings by Dedinec \& Dedinec (2017) and Dedinec \& Dedinec (2018), forecasting errors of these models fall within the range of $9.74 \%$ for EGARCH t model, $9.28 \%$ for ANN, and $9.07 \%$ for DBN method. As the results have shown, ARMA-GARCH constitutes a highly competitive model to forecast prices on the SEEPEX market. The comparison should be taken with reservation though, due to different research periods, the length of the analysed series and different data frequencies that have been used.

Table 9: Akaike's information criterion and Bayesian's information criterion for the selection of GARCH type model to best fit the data

\begin{tabular}{|l|c|c|c|}
\hline \multicolumn{1}{|c|}{ GARCH type models } & LLF & AIC & BIC \\
\hline GARCH Gaussian & 867.6866 & -1721.373 & -1684.604 \\
GARCH t & 992.5241 & -1969.048 & -1927.026 \\
EGARCH Gaussian & 894.9306 & -1773.861 & -1731.839 \\
EGARCH t & 1006.177 & -1994.353 & -1947.078 \\
GJR GARCH Gaussian & 891.1066 & -1766.213 & -1724.191 \\
GJR GARCH t & 1005.05 & -1992.1 & -1944.825 \\
SAGARCH Gaussian & 879.594 & -1743.188 & -1701.166 \\
SAGARCH t & 998.0995 & -1978.199 & -1930.924 \\
\hline
\end{tabular}

Source: Authors' calculations

The predicted values of the EGARCH t conditional variance are displayed in Figure 3, presenting the behaviour of volatility more clearly, and comparing it with actual in-sample volatility. It is evident that this model provides for a good in-sample fit and future volatility forecasting.

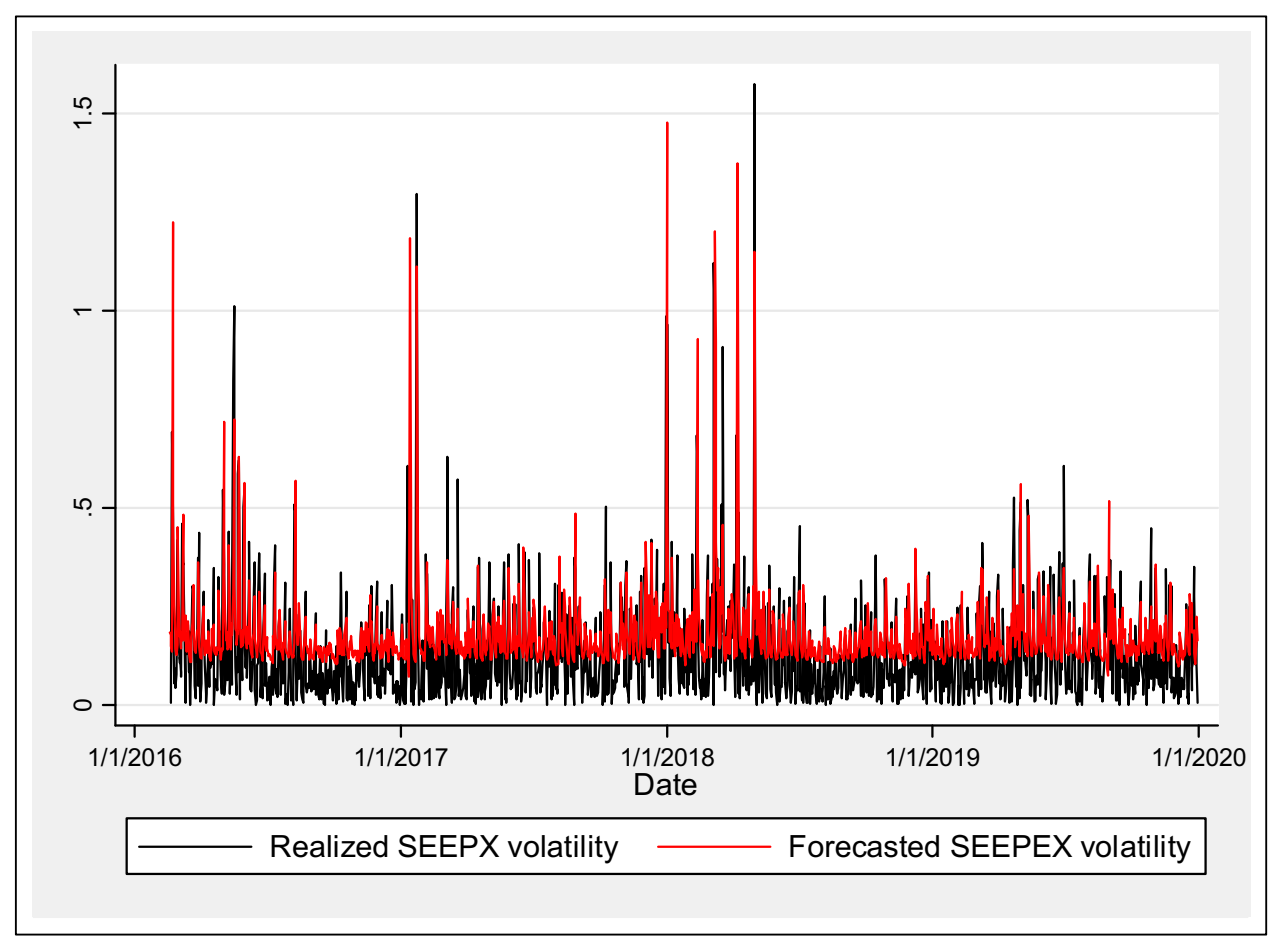

Figure 3: Graph of the one step ahead within sample estimates of SEEPEX volatility via EGARCH model with student-t error distribution and realized volatility data 


\section{Conclusion}

Modelling and forecasting electricity price volatility has been the subject of intensive research over the past ten years. Different approaches to forecasting and a variety of forecasting methods have been proposed for different markets. On the other hand, there have not been many attempts so far to analyse and predict the dynamics of electricity prices on Serbian power markets. Hence, the main contribution and significance of this paper lie in an attempt to fill this research gap by developing empirical time series forecast models for this market. This research is a novel approach, differing from the published work of other authors.

The aim of this study is to introduce and identify a short-term electricity price volatility forecasting model based on a statistical approach addressing the problems of price volatility in the newly developed day-ahead SEEPEX power market. Using descriptive statistics and appropriate tests, a number of statistical indicators have been obtained and employed as guidelines to conclusive findings related to the problem of predicting the volatility of electricity prices. A comparison between different ARMA-GARCH models with specific characteristic has been performed and discussed.

In this study, symmetric and asymmetric univariate ARMA-GARCH models have been used to capture the characteristics of electricity price returns. They assess the volatility of returns on SEEPEX power exchange. The LLF, the AIC and BIC have been implemented to evaluate the models' fit and the forecasting accuracy of GARCH models. The results show that the exponential GARCH model with student-t error distribution has the best overall performance for modelling the SEEPEX return volatility and is in general very effective in modelling and forecasting volatility. The other asymmetric models, GJR and SA GARCH, are also competitive. The widely used "plain vanilla" GARCH model performs well, but it has been outperformed by more sophisticated models that allow for asymmetry. Another conclusion is that SEEPEX time-varying volatility is more reactive and less persistent to market events during the observed period and has an inverse leverage effect.

This paper provides some useful insights for future research. The obtained results are all the more important as the domestic literature does not seem to have explored this issue sufficiently, providing greater practical implications and making the study's findings more useful to practitioners. Forecasting movements in the cost of electricity production and consumption is extremely complex due to the diversity and multitude of factors involved. With this in mind, the authors will shift the focus of their future research to identifying the main exogenous risk factors that can explain the variation of electricity prices on SEEPEX, finding and applying other multivariate time series models in combination with artificial intelligence, in order to be considered as an alternative to the approach adopted in this paper. Further, the research will be extended to other emerging regional power markets in order to compare their performance and pinpoint the most effective forecasting model.

\section{REFERENCES}

[1] Alexander, C. (2008). Practical financial econometrics. Chichester, England: John Wiley.

[2] Abedinia, O., Amjady, N., Zareipour, H. A. (2017). New feature selection technique for load and price forecast of electrical power systems. IEEE Transactions on Power Systems, 32, 62-74. DOI: 10.1109/TPWRS.2016.2556620

[3] Alfares, H. K. \& Nazeeruddin, M. (2002). Electric load forecasting: Literature survey and classification of methods. International Journal of Systems Science, 33(1), 23-34, DOI: 10.1080/00207720110067421.

[4] Awartani B. M. A., Corradi V. (2005). Predicting the volatility of the S\&P500 stock index via GARCH models: The role of asymmetry. International Journal of forecasting, 21, 167-183. DOI: 10.1016/j.jforecast.2004.08.003

[5] Bollerslev, T. (1986). Generalized autoregressive conditional heteroskedasticity. Journal of Econometrics, 31, 307-327.

[6] Cerjan, M., Petricic, A. \& Delimar, M. (2019). HIRA Model for Short-Term Electricity Price Forecasting, Energies, 12, 568. DOI: 10.3390/en12030568

[7] Chang, C.-L., McAleer, M. \& Tian J. (2019). Modeling and Testing Volatility Spillovers in Oil and Financial Markets for the USA, the UK, and China, Energies, 12, 1475. DOI: 10.3390/en12081475

[8] Chang, C.-L., McAleer, M. (2017). The correct regularity condition and interpretation of asymmetry in EGARCH. Economics Letters, 161(C), 52-55. DOI: 10.1016/j.econlet.2017.09.017

[9] Dedinec, A. \& Dedinec, A. (2017). Electricity price forecasting of the South East European power exchanges. In: Zdravkovic, M., Konjovic, Z., Trajanovic, M. (Eds.) ICIST 2017 Proceedings 1, 33-37. Retrieved from:http://www.eventiotic.com/eventiotic/library/paper/269

[10] Dedinec, A. \& Dedinec, A. (2018). Deep Belief Networks for Electricity Price Forecasting. In: Konjovic, Z., Zdravkovic, M., Trajanovic, M. (Eds.) ICIST 2018 Proceedings 1, 155-158. Retrieved from: http://www.eventiotic.com/eventiotic/library/paper/391 
[11] Enders, W. (2010). Applied econometric time series. 3'rd ed. Hoboken N.J.: John Wiley and Sons.

[12] Engle, R. F. (1990). Stock volatility and the crash of '87: Discussion. Review of Financial Studies, 3(1), 103-106. Retrived from: https://ideas.repec.org/a/oup/rfinst/v3y1990i1p103-06.html

[13] Engle, R. F. \& Ng, V. K. (1993). Measuring and Testing the Impact of News on Volatility. The Journal of Finance, 48(5), 1749-1778. DOI: 10.1111/j.1540-6261.1993.tb05127.x

[14] Gianfreda, A., Ravazzolo, F. \& Rossini, L. (2020). Comparing the forecasting performances of linear models for electricity prices with high RES penetration. International Journal of Forecasting, 36(3), 974986. DOI: 10.1016/j.ijforecast.2019.11.002

[15] Gianfreda, A. (2010). Volatility and volume effects in European electricity spot markets. Economic Notes, 39(1-2), 47-63. DOI:10.1111/j.1468-0300.2009.00220.x

[16] Glosten, L. R., Jagannathan, R., \& Runkle, D. E. (1993). On the relation between the expected value and the volatility of the nominal excess return on stocks. Journal of Finance, 48(5), 1779-1801. DOI: 10.1111/j.1540-6261.1993.tb05128.x

[17] Gonzalez, V., Contreras, J. \& Bunn, W.D. (2012). Forecasting power prices using a hybrid fundamentaleconometric model. IEEE Transactions on Power Systems, 27(1), 363 - 372. DOI: 10.1109/TPWRS.2011.2167689

[18] Hubicka, K., Marcjasz, G. \& Weron, R. (2019). A note on averaging day-ahead electricity price forecasts across calibration windows. IEEE Transactions on sustainable energy, 10 (1), 321-323. DOI:10.1109/TSTE.2018.2869557

[19] Kostrzewski, M. \& Kostrzewska, J. (2019). Probabilistic electricity price forecasting with Bayesian stochastic volatility models. Energy Economics, 80(C), 610-620. DOI: 10.1016/j.eneco.2019.02.004

[20] Liu, H. \& Shi, J. (2013). Applying ARMA-GARCH approaches to forecasting short-term electricity prices. Energy Economics, 37, 152-166. DOI: 10.1016/j.eneco.2013.02.006

[21] López-Gonzales, J.L., Souza, R.S, Coelho da Silva, F.L., Carbo-Bustinza, N., Ibacache-Pulgar, G. \& Calili, R.F. (2020). Simulation of the Energy Efficiency Auction Prices via the Markov Chain Monte Carlo Method. Energies, 13, 4544. DOI: 10.3390/en13174544

[22] Maciejowska, K., Nitka, W. \& Weron, T. (2019). Day-Ahead vs. Intraday-Forecasting the Price Spread to Maximize Economic Benefits. Energies, 12, 631. DOI: 10.3390/en12040631

[23] Maciejowska, K. \& Weron, R. (2019). Electricity Price Forecasting. In Wiley StatsRef: Statistics Reference Online (eds N. Balakrishnan, T. Colton, B. Everitt, W. Piegorsch, F. Ruggeri and J.L. Teugels). DOI: 10.1002/9781118445112.stat08215

[24] Maciejowska, K. \& Weron, R. (2015). Forecasting of daily electricity prices with factor models: utilizing intra-day and inter-zone relationships. Computational Statistics, 30, 805-819. DOI: 10.1007/s00180-0140531-0

[25] Maciejowska, K. \& Weron, R. (2016). Short- and mid-term forecasting of baseload electricity prices in the U.K.: the impact of intra-day price relationships and market fundamentals. IEEE Transactions on Power Systems, 31 (2), 994-1005. DOI: 10.1109/TPWRS.2015.2416433

[26] Maksimov, A.G. \& Shchurupova, D.V (2017). Forecasting of the electricity price on the day ahead electricity market in Russia. Cogent Physics, 4: 1316953, 1-8. DOI: 10.1080/23311940.2017.1316953

[27] Monteiro, C., Ramirez-Rosado, I.J., Fernandez-Jimenez, L.A. \& Conde, P. (2016). Short-term price forecasting models based on artificial neutral networks for intraday sessions in the lberian electricity markets. Energies, 9(9), 721. DOI: 10.3390/en9090721

[28] Mandal, P., Senjyu, T., Urasaki, N., Funabashi, T. \& Srivastava, A.K. (2007). A novel approach to forecast electricity price for PJM using neural network and similar days method. IEEE Transactions on Power Systems, 22(4), 2058-2065.

[29] Nakamura, M., Nakashimab, T. \& Niimura, T. (2006). Electricity markets volatility: Estimates, regularities and risk management applications. Energy Policy, 34(14), 1736-1749. DOI:10.1016/j.enpol.2004.12.019

[30] Nelson, D. B. (1991). Conditional heteroskedasticity in asset returns: A new approach. Econometrica, 59(2), 347-370. DOI: 10.2307/2938260

[31] Nomikos, N. \& Andriosopoulos, K. (2012). Modelling energy spot prices: Empirical evidence from NYMEX. Energy Economics, 34(4), 1153-1169. DOI: 10.1016/j.eneco.2011.10.001

[32] Nowotarski, J. and Weron, R. (2018). Recent advances in electricity price forecasting: a review of probabilistic forecasting. Renewable and Sustainable Energy Reviews, 81(P1), 1548-1568. DOI: 10.1016/j.rser.2017.05.234

[33] Serbian Power Exchange SEEPEX. (2020). Internet resource accessed on 1 March 2020. Retrieved from http://www.seepex-spot.rs

[34] Singh, N. \& Mohanty, S.R. (2015). A review of price forecasting problem and techniques in deregulated electricity markets. Journal of Power and Energy Engineering, 3(9), 1-19.

[35] Sisodiaa, G. S., Soares, I., Banerjic, S. \& Van den Poel, D. (2015). The Status of Energy Price Modelling and its Relevance to Marketing in Emerging Economies. Energy Procedia, 79, 500-505. DOI: 10.1016/j.egypro.2015.11.525 
[36] Steinert, R. \& Ziel, F. (2019). Short-to mid-term day-ahead electricity price forecasting using futures. Energy Journal, 40(1), 105-127. DOI: 10.5547/01956574.40.1.rste

[37] Wang Y. \& Wu C. (2012). Forecasting energy market volatility using GARCH models: Can multivariate models beat univariate models? Energy Economics, 34(6), 2167-2181.

[38] Weron, R. (2014) Electricity price forecasting: A review of the state-of-the-art with a look into the future. International Journal of Forecasting, 30 (4), 1030-1081. DOI: 10.1016/j.ijforecast.2014.08.008

[39] Zakoian J-M., (1994). Threshold heteroskedastic models. Journal of economic dynamics and Control, 18(5), 931-955.

[40] Ziel, F. \& Weron, R. (2018). Day-ahead electricity price forecasting with high-dimensional structures: Univariate vs. multivariate modelling frameworks. Energy Economics, 70(C), 396-420. DOI: 10.1016/j.eneco.2017.12.016

Received: 2020-06-30

Revisions requested: 2020-11-05

Revised: 2020-11-23

Accepted: 2021-01-09

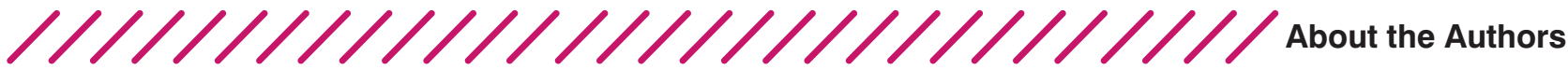

Ivica Terzić
Singidunum University, Faculty of Business, Belgrade, Serbia
iterzic@singidunum.ac.rs

Ivica Terzić is an Associate Professor at the Faculty of Business, Department of Finance and Banking, Singidunum University, Belgrade. He teaches courses in Portfolio Management, Banking, Monetary Economics and Models of Risk Distribution in

Financial Business. His professional interests refer to financial markets, risk management, financial risk forecasting, risk modelling, portfolio management, data analytics and energy markets. He has published numerous scientific papers, including the book "Financial markets and portfolio management". Currently, he participates in the international project "Experience-sharing of Visegrad countries to tax avoidance activity" (No.22010083), financed by International Visegrad Fund.

\section{Zoran Jeremić \\ Singidunum University, Faculty of Business, Belgrade, Serbia zjeremić@singidunum.ac.rs}

Zoran Jeremić, after graduating from Faculty of Economics in Belgrade, was employed at a bank, and then at the National Bank of Serbia. As an expert of the Bank Rehabilitation Agency, he was twice the Director General of the Banks in the process of rehabilitation. He was also the Director General of the Belgrade Stock Exchange and Chairman of Supervisory Bord of Belgrade Chamber of Commerce. He is a full-time professor at the Singidunum University, Faculty of Business, Belgrade.

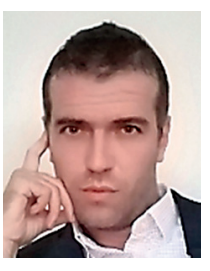

Tatjana Latas Somborelektro d.o.o. Sombor, Serbia tatjana.latas@somborelektro.rs

Tatjana Latas is a PhD student at Singidunum University. During her professional career, she has gained a wide range of knowledge and skills in various fields and has significant experience at leading position in the private sector. Her scientific field is liberalization and deregulation of electricity markets and her research interest is focused

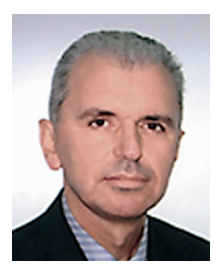
on power exchanges and risk hedging on electricity markets.

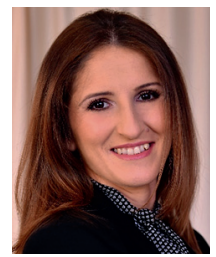

